\title{
Doing the Work of Medicine? Medical Television Programmes and Patient Behaviour
}

Tim Boon, Jean-Baptiste Gouyon

\begin{abstract}
This article explores the contribution of television programmes to shaping the doctor-patient relationship in Britain in the Sixties and beyond. Our core proposition is that TV programmes on medicine ascribe a specific position as patients to viewers. This is what we call the 'Inscribed Patient'. In this article we discuss a number of BBC programmes centred on medicine, from the 1958 'On Call to a Nation'; to the 1985 'A Prize Discovery', to examine how television accompanied the development of desired patient behaviour during the transition to what was dubbed "Modern Medicine" in early 1970s Britain. To support our argument about the "Inscribed Patient", we draw a comparison with natural history programmes from the early 1960s, which similarly prescribed specific agencies to viewers as potential participants in wildlife filmmaking. We conclude that a 'patient position' is inscribed in biomedical television programmes, which advance propositions to laypeople about how to submit themselves to medical expertise.

Inscribed patient; doctor-patient relationship; biomedical television programmes; wildlife television; documentary television; BBC Horizon
\end{abstract}

\section{Introduction}

Television programmes on medical themes, it is true, are only varieties of television programming more broadly, sharing with those others their programme styles and 'grammar'. But they also have a distinctive relationship to the practice of medicine whenever they represent doctor and patient behaviour. This

Tim Boon, The Science Museum, London, Tim.Boon@sciencemuseum.ac.uk Jean-Baptiste Gouyon, UCL Department of Science and Technology Studies, j.gouyon@ucl.ac.uk 
essay accordingly explores whether medical television departs from the rest of television specifically because of the subject position that medical programmes encode for viewers as health subjects and as potential patients. We consider whether the address to the viewer in their health identity - that is as the potential bearers of ill health - makes these films and programmes different from others that invoke the viewer in less intimate ways less coloured by the power relations of authority and supplication to authority. ${ }^{1}$ To put it another way: given that in Britain, the decades of the establishment of televisual grammar were also those in which the nation adjusted to universal healthcare, did films and television programmes serve to provide models for people of how to behave as patients? And, did that change across the era of social revolution of the Sixties, and beyond? If so, these media would indeed have been doing the work of medicine. As Alex Mold has argued, it was in the following decade, the 1960s, that ideas of consumerism began to be applied to patients, with the formation of bodies such as the Patients Association in 1962 and the Community Health Councils from 1974, extending into the medical context the kinds of attitudes found earlier in other aspects of life with, for example, the Consumers Association from $1956 .{ }^{2}$ It follows that it should be possible to see in broadcast programmes a developing range of patient roles across the examples we have selected for this essay.

Our contention is an extension of a previous suggestion that studying media can provide an alternative path to the cultures of bio-medicine, in the sense that study of the television programmes we consider here can provoke consideration of the history of clinical encounters beyond those internal to medical practice itself. ${ }^{3}$ Clearly, within the constraints of a short essay, it is not possible to follow all the implications of our contention into the larger literature on the history of the doctor-patient encounter.

\section{The 'Inscribed Patient'}

Our core proposition that medical moving image media suggest a particular subject position to viewers derives from some quite old media theory. ${ }^{4}$ Forty years ago, film theorist Bill Nichols wrote about the 'mode of address' of

1 Dominance/submission or status differentials are obviously complex social phenomena that we cannot begin to address here, but for a different, dramaturgical, angle, see Johnstone 1981, 36: "I should really talk about dominance and submission [rather than status], but I'd create resistance".

2 Mold 2015, 1.

3 Boon 2011.

4 Boon 2018. 
films. ${ }^{5}$ For our purposes, this may be taken to describe the tone of voice in which a film speaks to its audience, which might be called the 'cinematic voice of medicine'. More broadly, he argued that different genres of film, by using different modes of address, assert particular relationships to exist between the individuals seen and heard in films and the audiences watching them. Mode of address may be 'direct' as is found in most instructional and documentary films, where an individual - often an unseen narrator - speaks directly to people viewing. According to Nichols, in films using a fictional form, the mode of address is 'indirect', where the audience member 'overhears' the exposition between participants on screen and follows the action through identification with the film's characters. This maps pretty well onto the old distinction between telling versus showing. Each of these modes implies a position for the viewer in relation to the film and its authors; active in the case of the direct address of the documentary, and passive in the case of the indirect address of the fiction film. This had been a commonplace of documentary theory and practice for forty years when Nichols published. ${ }^{6}$ Madeleine Akrich, working within science and technology studies, has more recently suggested that the designers of technical artefacts inscribe a 'script' within an object, by which she means that the design of an object anticipates that its consumers will use it in particular ways, whether or not they do. ${ }^{7} \mathrm{By}$ metaphorical extension we can say the same of films and television programmes; that the viewer is 'inscribed' in the programme. Where we are talking about films or programmes with specific health education aims, the metaphor with Akrich's model holds directly because here the audience member is deliberately addressed as a potential patient. With documentaries about medicine, by contrast, the address to viewer as patient is incidental. Our argument is that television programmes that represent relations between doctors and patients also effectively make propositions about what those relations should be like, particularly about how patients are expected to behave - the subject position of the viewer-as-patient is inscribed in the programme, not as a deliberate act by the producer, but as a by-product of the programme's grammar, including its differing modes of indirect and direct address. To be clear: we are not proposing that programme makers set out to convey models of patienthood to viewers, still less that the BBC connived with the NHS to embed such models, rather that programmes about the clinical encounter inescapably incorporate representations of patient behaviour. Furthermore, in making our proposition, we intend to encourage scholarly

5 Nichols 1976.

6 Boon 2018.

7 Akrich 2003. 
reflection on how television might inform behaviour, rather than working at the close empirical level of seeking to establish whether or not this actually took place; such an analysis would require a substantial and difficult research project of its own.

The example of 'On Call to a Nation', a film made for BBC television by Richard Cawston, broadcast on 22 October 1958, can be used to explore this principle. This programme was an enquiry into the National Health Service (NHS) ten years after its foundation. Cawston, within a few years to become Head of BBC Documentaries, set out to make a film for television that, as he stated, 'is in no way intended to be a technical or scientific film but will be a social documentary about people and ideas, and it will attempt to show what has happened to the public and to the doctors and what they think ought to happen next'. ${ }^{8}$ Coming ten years after the 1948 launch of the NHS, which for the first time provided healthcare free at the point of use to the whole British population, the programme is not in the business of explicitly demonstrating, on behalf of the state, how citizens should use the service as they had in 1948, for example, in the memorable 'Charley' short films made by the animators Halas and Batchelor. ${ }^{9}$ The script of 'On Call to a Nation' proclaims, 'That was ten years ago, and now we take it all for granted'; the purpose of the film is to investigate how it's all going.

The structure of the programme, using patient journeys as its main structural device, enables us to interrogate these patient roles. It starts with a caption asserting 'in the film that follows there are no actors'. In the opening sequence, we see a male GP going through his morning post with a nurse in attendance. The sequence concludes with him asking 'now how many patients are waiting? ... Well, I'll ring when I'm ready'. A vision cut to a waiting room follows; we hear a simple double bass melody played pizzicato; the programme's title is superimposed. The camera tracks past the waiting patients, and a rolling caption states 'this is about doctors - and the National Health Service as they see it, ten years after it started'. The commentary commences, giving a brief account of the foundation of the NHS over shots of five of the doctors we will meet later in the programme, before a return to the waiting patients. We hear the sound of the doctor's buzzer (the music continues); a young woman with baby gets up; the opening commentary concludes with the question 'but what do doctors think about it now?' The vision cuts to the doctor's room as this first patient enters. Cawston's structure uses this GP's waiting room as a device, with the bass leitmotif and GP's

8 ER Cawston to H.T.Tel, "60 Minute Programme - Ten years of State Medicine”, T32,1,333/1, BBC Written Archives Centre, Caversham (hereafter 'BBCWAC').

9 Leab 2005, 234-6. 
buzzer, to introduce a series of different health services by following individual patients with particular conditions into particular aspects of the NHS's functioning or into specialist services (including how GPs are paid, the administration of prescription costs, access to hospital diagnostic services and community services including ophthalmology and dentistry). The invitation to viewers of the programme is to identify with the patients in the programme just as in Nichols' theory they might identify with the participants in a fiction film; to think of themselves as being like the people in the waiting room as an imaginary path is laid out for them as people travelling into the services of the NHS. The proposition the programme makes via its mode of address to viewers is to imagine themselves playing the part of the patient, just as they see the 'real people' of Cawston's TV film provide just such performances of self. ${ }^{10}$

One of these sequences explicitly addresses the doctor-patient relationship. We see a patient, 'Mrs Radcliffe', visiting the GP, requesting a tonic on account of tiredness; the GP books her a separate, longer, appointment. The commentary voice takes over the exegesis, and we see on screen a middle-aged GP, who earlier in the programme has shown himself to be critical of younger doctors' prescribing practice. The commentator asks:

How does a GP organise his [sic] time and is his time abused? Do people call the doctor out for trivialities or flock to his surgery without good reason? In fact, has the NHS bred a nation of hypochondriacs, as was once predicted? Some GPs say there are certain patients who always waste their time, and they get to know them.

This doctor, in direct address to camera lists kinds of patients:

There is the patient who says, after you have examined her: 'ooh, whilst I'm here, doctor', and then produces a string of further unrelated symptoms. There is the patient who stops you in the street and tries to get a consultation or asks for a prescription to be left for this, that or the other. There is the patient who sends for you, and when you get there, you find not one patient, but several lined-up for examination. And there are the patients who send-in late. And it is so helpful to a doctor, in arranging his day, and the best use of his time, to have his calls sent in before he leaves the surgery in the morning.

Two succeeding doctors, also in direct address to camera, are significantly more emollient. The first, a Scottish GP, previously identified as practising at a former panel practice in a densely populated working-class district of London, explains:

I sometimes feel that a patient visit is unnecessary, and that it is frivolous, but of course there is no such thing as a frivolous visit to the doctor; the patient is bound to have some underlying anxiety or reason for his visit, and it is my business, and my duty, to reassure him and if possible, send him away happy.

10 Boon 2020. 
This sequence, which goes on to explore the organisation of GPs' time, is interesting for our analysis of the patient role; the invitation to the viewer must inevitably be to consider whether they are themselves 'time wasters', or whether they have an 'underlying anxiety'. The direct address of the different doctors is also significant, as it televisually gives access to opinions about patients normally hidden from them that might also indirectly colour patient expectations of the clinical encounter. The attitude of both the doctors quoted places them hierarchically above their patients, whether the tone is more paternalistic or more critical. In both cases - patients and doctors - it is helpful to think in the terms of the sociologist Erving Goffman who, in his work on the performance of self in everyday life, distinguished between the impressions that people give consciously, and those that they 'give off' undeliberately. ${ }^{11}$ Within the programme, the general practitioners (like all the doctors, never named, as was the convention at the time) give performances of easy authority, and give off impressions of varying levels of confidence ranging from considerate reflection on patient subjectivity to borderline arrogance. The patients (all named) give off a deferential impression, as was also in the case of 'Your Life in Their Hands', broadcast six months earlier. ${ }^{12}$

In playing their roles, Cawston allows some individual patients to transgress strict politesse, as is visible in two further examples. 'Mr Day' comes for a repeat prescription for a heart complaint. The doctor will not permit him to return to work yet. But, with his core business complete, the patient asks for an indigestion medicine for a 'Mrs Botley'. The GP gently rebuffs him: 'you tell Mrs Botley she'll have to come and ask for that herself, you see, because I don't like giving medicine to people if I don't know what's the matter with them'. This introduces a sequence on how the prescription service works. Later in the programme, the GP speaks to 'Mr Sapsford', an elderly male patient awaiting an operation for painful veins. In vision he asks pleadingly 'when could you get me into hospital, sir?' The film cuts to the GP, who explains 'You're not an urgent case, and the trouble is that the beds are used for the urgent cases first, before they can get non-urgent cases like you in. I tell you what I'll do'. The film cuts to the patient listening; the doctor continues, 'I'll ring up the hospital and I'll find what your position on the waiting list is. Is that alright?' The patient responds 'Will you tell them that I'm fed up with waiting?' The doctor answers 'yes, well I may do'. This, in its turn, introduces a sequence on hospital services and waiting lists. The point of both these patient performances is that whilst the amateur actors were

11 Goffman 1990.

12 Boon 2020. 
clearly given a scenario that assists the exegesis of the film, they also present to the viewer a possible mode of patient behaviour which, while deferential, gives them a very limited degree of agency.

The years of the bedding-in of the NHS were also those of the development of televisual grammar attuned to a mass viewership. Cawston's film is interesting in that respect. This is a film shot and edited prior to broadcast, unlike the great majority of broadcast television in 1958, which was live. ${ }^{13}$ Despite this, by 1958, documentaries made on film for broadcast had already developed characteristics that distinguished them from what are generally thought of as 'classic' British documentaries. We see some of these in this example. The film retains the older practice of having an off-screen narrator, Colin Wills, although this is not a 'voice of God' narration telling the viewer what to think, rather Wills, voicing words written by Cawston, provides the tissue of connections between speakers and lays out factual information appropriate to each sequence. ${ }^{14}$ But much of the fine texture of the programme, especially in the statements of opinion from the doctors, is of direct address to camera, a technique rarely seen within the standard technique of older documentary films made for projection in public spaces. Camera-framing of the participants is also significant; we should pay attention to the use of close-ups that serve to reinforce the emphasis of the views they voice, for example. And we should note visual cues that tell us the extent to which the participants are speaking 'off the cuff', working from cue cards, or performing detailed scripts; most of the doctors' performances here are about half-way between these extremes: rehearsed and assisted by cues, as there is evidence of eye movement suggestive of reading. Their degree of fluency has a direct bearing on the impression they 'give off' to the viewer. And the director's choice of camera-angle and framing reinforces that effect. For a viewer today, the social attitudes encoded in the film mainly seem archaic, with paternalism and deference being the order of the day. It is harder, of course, to come to an understanding of what contemporary viewers thought of it, and that is not the point of the kind of analysis presented here.

We also need to understand that, as with very many non-fiction programmes, to get performances of the right kind for the programme, the director needed to do significant preparation, finding articulate participants, persuading them of the merits of appearing on television (which some doctors felt to be ethically questionable ${ }^{15}$ ), then making them feel comfortable

13 Boon 2008, e.g. 207, 219.

14 Here we concur with Stella Bruzzi's proposal that we should move away from the cliché in documentary studies that all narration is paternalistic and controlling. Bruzzi 2006.

15 Loughlin 2000. 
when it came to the shoot. Unlike live TV, on film it was possible - up to a point - to do a re-take to get a better performance, but directors were obliged not to waste film; all filmmakers were constrained to work within particular 'shooting ratios' - between the footage used in the final programme and that not. One point worth making here is the effect of filmmaking, rather than televisual, technique on performances: individual 'takes' may have been quite disjointed and individually rather short - minutes or seconds, even and the final flow was constructed after the event in the editing room employing the most usable performances from both GP and patient. With respect to the performances demanded of the participant, this needs different kinds of concentration from the participants than that required by live programmes, where all of what the participants do is seen by the camera, and the audience. But we should note a textural difference between the programme's structural staged sequences of the GP with his patients and the opinion sequences of the selected and various doctors who appear throughout. The doctors' opinion sequences are not unlike those that occurred in contemporary live television; they are informal and not scripted in fine detail. This is needed, not least because the interactions between GP and patients are in 'indirect' mode; they have something of the 'overheard' quality of fiction.

The examples quoted here are sufficient to make the case that, whenever television documentaries show the interactions of patients and doctors, they inscribe a role for the viewer as potential patient. Or, in this case, a variety of roles. 'On Call to a Nation' locates these viewer-patients explicitly in relation to the affordances and constraints of the NHS as it was responding to demand a decade after its launch.

\section{Comparison with Natural History Television}

As we argue, medical programmes share a great deal with other kinds of programmes. It makes sense then to look for evidence of whether programmes on subjects other than medicine invite viewers to assume particular roles as we have seen in the case of patients, and to play them in particular ways. We argue that many kinds of documentary television, in their mode of address, do propose kinds of action and behaviour for viewers, especially when these documentaries depict activities or occupations in which viewers could potentially take part. For example, natural history television can be said to have offered viewers a model of how they might become amateur wildlife cameramen, just as medical documentaries presented viewers with a model to be patients. Our point is not to suggest that a patient and an amateur wildlife cam- 
eraman operate on the same symbolic level. In particular, the patient-doctor relationship is about how people interact within a politically charged, hierarchical setting, which would not be the case with the behaviour of an amateur naturalist in the field. Yet, this comparison is relevant because our examples were broadcast at a time when the BBC Natural History Unit (NHU) was attempting to recruit new contributors, wildlife cameramen, to provide the $\mathrm{BBC}$ with original film material. These films were intended to provide viewers with role-models if they wanted to become contributors to the NHU, which would placed them in a hierarchical setting.

The films we look at for this comparison were produced in the early 1960s, when the NHU was consistently drawing smaller audiences than their competitors, the various ITV producers of wildlife TV programmes. ${ }^{16} \mathrm{To}$ address this issue, the NHU seized on an earlier proposal from The Nature Conservancy (a global conservation charity founded in 1951), to use their 'immense power' to shape the field of amateur natural history in Britain and to use the contents of their programmes to encourage people to become wildlife cameramen. ${ }^{17}$ One of their attempts involved presenting one of their contributors, Eric Ashby, as the paragon of the amateur naturalist cameraman. Ashby had come to the attention of the NHU through film reels he had sent depicting, notably, badgers filmed in full daylight and behaving naturally. At the time this was considered a feat. Ashby's work appeared in the first filmed feature originating from Bristol, 'The Unknown Forest', broadcast in January 1961, which celebrated the wildlife of the New Forest in Hampshire. The film's commentary extolled the value of blending into the landscape for anyone who wished to obtain true knowledge of wildlife. Viewers were treated to visual records of what deer, badgers, foxes or hedgehogs are up to in the forest when left alone, or if they are unaware of the presence of human observers. Following the film's success with audiences, Ashby briefly became a wildlife personality and his work regularly featured in episodes of the natural history television series 'Look', the NHU's flagship programme in the early 1960 s, hosted by celebrity naturalist Peter Scott. As was usual in this series, Ashby appeared alongside Scott, to explain how he had obtained his footage. But the format of these appearances departed from the norm for the series. These can be seen as instances where the NHU, by providing viewers with a role model in the person of Eric Ashby, attempted to normalise the behaviour in the wild of would-be wildlife cameramen.

16 Gouyon, 2019.

17 E. M. Nicholson to Desmond Hawkins, personal letter, 7th July 1958, The National Archives, FT 3/541. 
An example is the 1963 Look episode 'Forest Diaries'. This programme was filmed on location, which in the early 1960s was not uncommon at a time when the series was progressively escaping the studio. ${ }^{18}$ What is striking here is the part Ashby plays. Guest filmmakers in Look usually talked to Scott, explaining what it had entailed to produce the footage shown in the programme. As ornithologist James Fisher (one of Scott's regular guests on TV, and himself host of radio programmes) put it in 1959:

None of the distinguished naturalists and cinematographers whom Peter Scott has introduced talk down to their public. Indeed, they talk, not to their public, so much as to each other in the relaxed yet lucid voices that they would use in any normal discussion of their profession amongst themselves. ${ }^{19}$

Yet, in 'Forest Diaries' Ashby is only heard in a voiceover commentary. When he appears on screen, he does not interact with Scott, nor does he seem aware of the camera's presence. Instead, he is seen in the background crawling in the undergrowth, more animal than human, whilst an impassive Scott delivers his commentary, in camera, as if Ashby were absent. The scene could be taken from a sketch from the Monty Python comedy series. In his commentary, Scott explains that Ashby is reproducing his behaviour when filming badgers in full daylight in front of Look's cameras for the benefit of viewers. The image then cuts to footage from Ashby's film on badgers, where he is seen with badgers frolicking around him, oblivious of his presence. The positioning of the camera for this footage, behind Ashby, compresses the perspective and creates the impression that the distance between the human and the animals is less than it really is. The whole sequence can be interpreted as demonstrating to viewers what results can be had if aspiring wildlife cameramen adopt the prescribed behaviour in the field.

With this example we can see television programmes working to suggest to viewers behaviours appropriate to specific circumstances. This sequence presents Ashby to audiences as an example of how would-be naturalist filmmakers should behave in the field if they want to be successful at obtaining wildlife footage valuable by the NHU. This episode of Look was broadcast at a time when the NHU was trying to recruit new contributors, at the same time as attempting to enforce standards of content and quality for the footage these new contributors could produce. A sequence like the one described above normalises behaviour in the field and signifies to aspiring wildlife cameramen that if they want to be able to participate in the produc-

18 Gouyon 2019.

19 Fisher 1959, 9. 
tion of natural historical knowledge on the BBC they should partly become animals.

But beyond prescribing behaviour in the field, this sequence helps to establish which position aspiring wildlife cameramen could hope to occupy in the ecology of wildlife television production in the early 1960s. Their participation cannot go beyond providing programme producers with the raw footage they need to create programmes. This Look sequence was broadcast at a time when, as already noted, the BBC NHU was developing several outward-facing initiatives to publicly fashion its institutional identity and to encourage people to make wildlife films. These included a course for aspiring wildlife cameramen, run with the Council for Nature, and for the purpose of which the NHU produced a 'demonstration film' showing how the Bristol Unit functioned to produce wildlife television programmes. ${ }^{20}$ 'Unarmed Hunters' (BBC, 1963) ascribed a very definite position in the ecology of programme production to wildlife cameramen operating in the field.

The desired stereotype was here again represented by Eric Ashby. 'Unarmed Hunters' celebrates machines, creating a very technical definition of wildlife television production, which contrasts with earlier public understandings of it as revolving around the figure of the adventurous wildlife cameramen. Mostly composed of two kinds of sequences, the film shows the people at work, dressed as office workers, and the equipment they use. As a film to instruct potential future contributors to the NHU, 'Unarmed Hunters' introduces viewers to the successive stages of programme-making and emphasises the manufactured nature of wildlife television programmes. The camera lingers over flatbed film editing suites (Steenbecks), stacks of reels, telecine machines, mixing consoles, and quarter inch tape decks, hands pushing buttons and turning knobs. The visual abundance of machinery, often looking complex, likens the production of wildlife television programmes to an elaborate industrial process, which only technical experts, wearing suits and ties, can adequately perform. By contrast, in this film Eric Ashby is seen from afar in the countryside, progressing in the undergrowth and carrying his $16 \mathrm{~mm}$ camera in a wooden box. Dressed for field work in tweeds and wellies, he appears alien to the machine-saturated atmosphere of 'Unarmed Hunters', his demeanour further distancing him from NHU workers, clad in suits and looking more like civil servants than gentlemen farmers.

A possible interpretation of this sequence, set within a film which ascribes a pivotal role to post-production in the ecology of wildlife televi-

20 Crocker, N., 'Natural History Unit Library', Personal letter to A.T. Callum, 7 August 1964. BBCWAC R125/829/1. 
sion-making, is to see it as attributing to wildlife cameramen a position at the periphery of the professional culture of wildlife television broadcasting that was being developed at the NHU in the early 1960s. This sequence, just like the whole film, invites viewers to participate, by providing the NHU with footage of wildlife, albeit limiting their role to that of external contributors. Within the context of the evolution of natural history filmmaking, such representations of amateur natural history cameramen signal the rise in power of the producer as the central figure of wildlife television to whose authority aspiring naturalist cameramen should submit themselves. ${ }^{21}$

The purpose of looking at these examples is to show that television representations of knowledge production enterprises - natural history here, but the phrase also encompasses medicine - that potentially involve viewers, can be analysed as providing these latter with role models, norming their participatory behaviour in these endeavours. As these sequences involving Eric Ashby suggest, such norming occurs both at the level of actual bodily, physical performances, but also with regards to positioning these participations within the ecology of these endeavours. Constructed as a role-model for aspiring amateur naturalist cameramen, Ashby defines the role as one that involves both an intimate connection with nature, the ability to blend into it (Ashby always appears more at ease with animals than with his fellow humans), and a submission to the authority of television producers. The sequences of wildlife television programmes examined here work to establish the hierarchical organisation of wildlife TV production in which viewers would have to insert themselves if they were to participate as contributors of footage, submitting themselves to the authority of producers. As we will now consider, Horizon episodes about biomedicine can similarly be analysed as establishing norms of behaviour for viewers to participate in healthcare as patients.

\section{Comparison with Medical Horizons}

Let us therefore wind forward to some examples of patients in documentary TV. In this case, let us go to Horizon, the flagship British science documentary series. For the purposes of this paper, we focus on four programmes selected from a dozen Horizon episodes broadcast between 1964 and the mid1980 s with a focus on medicine. These episodes belong in successive regimes of science television as exemplified in the series. When looking at the history

21 Gouyon 2019. 
of Horizon, the late Sixties are identified as the period when the series adopted a salient critical edge. The producers of the series at the time conceived of themselves as watchdogs. To them it was beyond discussion that, given the potentially deleterious effects of science on humanity's existence, their duty was to exert some kind of critical scrutiny over the development of science, technology and medicine. ${ }^{22}$ Instead in the 1980s the work of Horizon producers was more informed by the journalistic values of investigation, with the intention of providing audiences with a balanced coverage of these developments and establishing themselves as necessary intermediaries between an increasingly sophisticated scientific sphere and lay audiences. ${ }^{23}$ The episodes chosen for this study map this evolution from the 1970s critical scrutiny to that of the 1980s era, one in which informational objectivity was claimed for journalistic coverage.

This time span revolves around the restructuring of the NHS between 1968 and 1972, which was undertaken to improve managerial and administrative efficiency, connoting a decisive shift within technomedicine to the centrality of the hospital as the preferred location for treatment (as opposed to the home or the GP's surgery), and increasingly for scientific research too. This reorganisation of the health care system was symptomatic of a broader ongoing political debate over how much the NHS should take on non-curative roles. ${ }^{24}$ The programmes selected for consideration here therefore either address this transition as their main topic or represent the practice of medicine after the transition had taken place. Just as with the example taken from wildlife television, which did not set out to discuss the way wildlife cameramen should behave in the field but showed it nonetheless, none of these Horizon episodes directly set out to address the doctor-patient relationship. Yet they all feature a number of visual representations of this relationship, albeit in relation to narratives about doctors' training or the practice of medicine in hospitals. Like the examples featuring Eric Ashby discussed above, these Horizon episodes can all be interpreted as prescribing viewers a role to participate in medicine as patients.

22 Peter Goodchild (editor of Horizon, 1969-1976) interviewed in 1975, noted: "During the latter part of the $1960 \mathrm{~s}$, fairly obvious debates arouse about transplants for example, about chemical or biological warfare and so on, and these began to make journalists in general, the public in general, question where science was actually taking us. Then there was the whole environmental revolution, we were in the midst of that, and I think this has meant that everybody now has begun asking where science, which is you know, one of the main forces behind progress, behind the shape that society is going to take in the future, is taking us". (In Vision, BBC: 1975).

23 Hornig 1990; Boon and Gouyon 2014.

24 E.g. see Gill 1974; Klein 1972; Klein 1973. 
As these four programmes all focus on 'modern medicine' - in the sense outlined in the NHS reorganisation - it is hospital patients we mainly see. The displacement of healthcare from the GP's surgery to the urban hospital may have led the population in Britain to question the effect this change would have on the quality of the care they received. Particularly at stake here was the paternalistic doctor-patient relationship depicted for example in 'On Call to a Nation', discussed earlier. In the early 1970s, research-based medicine practised in the hospital was perceived as a rationalisation of healthcare, but one also with the potential to lead to the dehumanisation of the doctor-patient relationship. ${ }^{25}$ For producers, at stake when communicating about this transformation of medical practice was thus the necessity to convince potential patients that despite the transformation of this relationship, the quality of treatment was not diminished. But as the present analysis will show, these television documentaries depicting hospital-based healthcare also performed specific hierarchies and provided viewers with role-models suggesting to them how to behave under the benevolent authority of clinicians.

Another debate in this period of the late 1960s - early 1970s was about whether patients ought to be treated and empowered as consumers of healthcare services. Some commentators, such as the sociologist Margaret Stacey (1974), contended that 'medicine was a service industry that did things to and not for people; that the patient was both work object and social actor' (Mold, 2015, p.8). From this standpoint it was inappropriate to introduce a consumerist dimension in healthcare. The idea here was that the imbalance of expertise between patient and doctor was inherent to healthcare provision, and made it impossible to characterise patients as consumers; the inherent imbalance necessarily placed patients at a disadvantage when it came to knowing about their condition and appropriate treatment. This asymmetry 'of the doctor-patient knowledge-power relationship therefore made it difficult for patient-consumers to act as autonomous individuals' (Mold, 2015, p.8). From this vantage-point, the Horizon episodes discussed here can be interpreted as weighing into this debate, emphasising the necessary passivity of patients' submission to doctors' cognitive authority if healthcare was to work at all.

The 1971 Horizon episode 'What Kind of Doctor' considers doctors' training at St Thomas's Hospital in London in this context, asking whether they receive the appropriate training to become GPs. The programme sets out to explore whether medical students, despite increasingly being trained

25 Dopson 1971. 
to become clinicians, still retain the holistic approach to treatment which is said to be the hallmark of the GP in local communities. The programme's answer is to suggest that the solution to this dilemma rests with students, whose individual attitude will determine whether they will be able to strike the right balance between science and humanity. The main interviewees in the programme are teachers in the medical school or practising GPs, framing the debate as one internal to the profession. Patients, the most likely to be affected by the issue, are not given a word in the matter. Nor are they encouraged to participate in the debate. They are cast here as passive recipients of whatever health service the turn to scientific medicine yields.

To open the programme, the pre-title sequence offers an unambiguous depiction of patients' central yet passive role in 'modern medicine'. Following establishing shots of St Thomas hospital, presented in the commentary as 'one of the great teaching hospitals of London and the World' which was then being rebuilt 'to meet the higher standards of modern medicine' now that 'the treatment of diseases is transformed by science', the camera takes viewers inside one of the hospital's lecture theatres. There, a patient is shown being wheeled in and then undergoing an examination in front of the assembled students, to demonstrate his symptoms. During this performance of 'the medical gaze' (Foucault, 1963) in action, the patient, lying on a reclining chair, performs being ill, submitting himself to the clinician's inquiry. Although they share a space, the lecture theatre, at no point do students and patient directly interact, as if they were standing in two separated spheres. The clinician moves back and forth between these two discrete spheres. His discourse seamlessly changes from a direct address to the patient, asking him to perform certain tasks such as following the tip of a pen with his eyes, to describing the man's condition to the students using the third person singular, as if the patient were absent. When he does describe the patient's physical symptoms, the clinician manipulates him as an object, for example turning his head from left to right and back repeatedly to demonstrate that the affliction does not impede this movement. This programme presented as being about the doctor-patient relationship, introduces patients as little more than bystanders to a debate about their position in the healthcare system.

The following year, another Horizon episode seemed to give a more active voice to patients. The 1972, 'Are You Doing this for Me Doctor, Or Am I Doing it for You?' which, on the face of it, scrutinises who stands to benefit from scientifically informed healthcare, looked at a series of experiments conducted in different hospitals in the USA and the UK. It contrasts the case of the UK with that of the USA, pointing especially to an experiment 
whereby children had been 'voluntarily' injected with hepatitis in order to study the use of immunotherapy to treat them. The problem here was that the children were mentally disabled, and that neither they, nor their parents, had been made aware that they were subjected to such experiment. The programme followed a debate in November 1971, were allegations had been made that such experiments were taking place in an NHS hospital. The Ministry of Health had responded that even if such experiments were taking place in the US, they could not take place in the UK. ${ }^{26}$ The programme, based on a difficult case, interrogates the consequences of asking patients to surrender their agency, expressing fears about technomedicine. Contrasting the US and British cases, the programme reassured viewers that consent had been received for all experiments conducted on British patients. The 1971 and the 1972 programmes, which both presented themselves as questioning the authority of medicine, ultimately worked to reinforce it.

In the next two programmes, from a few years later, viewers are provided with examples of patients that suggest an almost complete surrender of their agency to the authority of medicine. The two programmes both relate to immunology and offer a portrayal of the use of antibodies as medical tools. The 1974 'A Matter of Self Defence' considers immunology broadly and moves from vaccination to bone marrow transplant and finally research on immunotherapy, notably in relation to cancer treatment. A sequence depicts a child, who has received a successful bone marrow transplant, during a follow-up consultation at the hospital. This sequence which is meant, within the programme, to illustrate the potency of immunotherapy, can be interpreted just like the sequence featuring Eric Ashby in the wild discussed earlier. It is staged so that the child, who is the main object of the sequence, epitomises all patients in the context of research-based medicine, and so serves as a model of behaviour. In the sequence, the clinician manipulates the boy's body and makes him lie-down, sit, stand-up, all the while talking to his mother, or to the camera. Parallels can be drawn with a sequence in the same programme which depicts lab-technicians manipulating rats. The patient's agency is minimal, his body a prop in the treatment process.

This way of representing patients as passive recipients of treatment in the modern, science-based hospital only gets more pronounced in the 1985 'A Prize Discovery'. ${ }^{27}$ Celebrating the achievement of Cesar Milstein, who in December 1984 had been rewarded with a shared Nobel Prize for his work on monoclonal antibodies, the purpose of 'A Prize Discovery' is to explain 
Milstein's work and to emphasise the progress it allows in medicine. For example, the programme emphasises the advances in the treatment of cancer which monoclonal antibodies have made possible, such as more targeted radiotherapy. ${ }^{28}$ In a sequence devoted to explaining how radioimmunotherapy works, a patient is shown being injected with monoclonal antibodies and then being placed underneath a scanner. The camera then cuts to a view of two doctors, seated in an adjacent room in front of a computer screen displaying a view of the patient's abdomen where tumours are highlighted. One of them comments on the image and goes on to explain the procedure the patient is undergoing.

These two programmes reiterate the lack of patient agency in the context of scientific medicine. They are seen as passive recipients of injections, lending themselves to being manipulated by clinicians, or submitted to the actions of machines. Comparing the 1974 Horizon programme with its 1985 counterpart reveals an enduring metaphor when it comes to the topic of immunology, that of warfare. In both programmes, the commentary is peppered with comparisons of antibodies and lymphocytes with defensive weapons. Antigens and infectious agents are likewise likened to invaders and offensive weapons. Unsurprisingly, the battlefield for the conflict thus outlined is the patient's body. The materiality of the body is transformed, turned into a computerised visualisation. But in this context, doctors' agency seems to be reduced too. It is limited to directing patients and administering the various treatments reviewed in these films. Ultimately, when it comes to curing disease, agency rests with non-human entities, monoclonal antibodies and other chemical compounds, or machines.

To paraphrase Michel Callon, the programmes analysed here create an actor-network that simultaneously gives rise to society and medicine. ${ }^{29}$ The practice of scientific medicine as portrayed there is only possible because of the social relationship between patients, doctors, and biochemical compounds similarly defined in these programmes. Patients passively submit themselves to doctors' actions, who themselves are ultimately subservient to the agency of antibodies and other biochemical compounds. Patients' participation in research-based healthcare is through the willing provision of their body as raw material on which doctors can unleash the power of modern science.

28 E.g. Kohler/ Milstein 1975.

29 Callon 1987, 99-100. This Actor Network could be defined as being composed of patients, doctors, medical students, machines [e.g. scanners, computers], molecules [e.g. monoclonal antibodies], but also the bureaucrats enacting political decisions such as Richard Crossman's decision, as the secretary of state for social services in Harold Wilson's government, to restructure the NHS around hospitals. 


\section{Doing the Work of Medicine?}

The examples of 'On Call to a Nation', natural history television and biomedical Horizon programmes demonstrate that it is possible to trace certain similarities between different genres of television made in the same broad synchronic bands of time. This parallels the finding that there were substantial similarities in the ways that television in the early 1960s represented members of the professions; whether those were scientists, literary authors or musical composers; all were treated with a deference that arose from the existing class relations of British society, conventions that were to be challenged by the 1960s social revolution. ${ }^{30}$ The similarity between medical and other non-fiction television extends to the concerns of this essay that television can serve to propose kinds of action and imagined roles to viewers; that too was found in non-fiction television with themes other than medicine, as we saw with the example of Eric Ashby.

It is helpful here to consider the nature of participation in medicine by patients and by doctors as kinds of activity. On analogy with Christopher Small's insightful verbing of the noun 'music' to create the new term 'musicking' to connote all musical activity, we propose thinking about participation in medicine, by all participants, as 'medicining'. Where Small writes that 'the fundamental nature and meaning of music lie not in ... musical works at all, but in action, in what people do', we may portray participation in medicine in the same way, repurposing Small to assert: To 'medicine' is to take part, in any capacity, in health, ill-health or its treatment, whether by doctoring, by being a patient, by living a healthy life (or not), by developing new treatments or taking them, by consuming health media ... and much else besides. ${ }^{31} \mathrm{Or}$, to put it very simply, being a patient is participation in the practice of medicine. The way in which this may be distinctive, in relation to the case of science in general, is that the power relations between medicine and patient gives authority to the doctor by virtue of the vulnerability of the patient, a state of affairs that has long been the concern of medical historians and sociologists. Then, again, the iterative performance of medical authority and patient vulnerability can be seen as constituting the doctor and patient roles. ${ }^{32}$ But our examples show that patients' deference to medicine and doc-

30 Boon 2017.

31 Derived from Small: "To music is to take part, in any capacity, in a musical performance, whether by performing, by listening, by rehearsing or practising, by providing material for performance (what is called composing), or by dancing”. Small 1988, 9.

32 Butler 1993; Boon 2020. 
tors persisted well beyond the supposed universal changes in social attitudes associated with the 1960s.

As we argue, the effect of television programmes proposing modes of behaviour by 'inscribing' patient behaviour in medical documentaries is an effect separate from the deliberate intentions of the programme makers. Indeed, the BBC's ethos of professional and medium-specific representational expertise was opposed to programmes deliberately becoming vectors for the views of other professional groups. Producers defined their practice as the exercise of specifically televisual skills, independent of the proponents of the subjects they represented, which Aubrey Singer expressed in a much-quoted 1966 lecture on science: 'the televising of science is a process of television subject to the principles of programme structure, and the demands of dramatic form ... in taking programme decisions, priority must be given to the medium rather than scientific pedantry'. ${ }^{33}$ In other words, making television programmes about science - or, in our case, medicine - was the business of television producers, not of scientists - or doctors. Producers saw themselves as masters of televisual technique, and that meant taking charge of the way the medium represented its subjects, without undue deference to how their subjects might have chosen to be represented. When television began seriously to make programmes about science and medicine, from the mid-1950s onwards, producers asserted this role. And it is true that organised and élite scientists found fault with science broadcasting, initiating a series of delegations to the BBC Director General in the late fifties and early sixties, in what was effectively a contestation of expertise between professional groups. ${ }^{34}$ On the medical side, there was also occasionally considerable disquiet when television producers made programmes that trespassed on their professional ethics; the best-known case is that of 'Your Life in Their Hands', which the BMJ represented as a betrayal of the sanctity of the doctor-patient relationship. ${ }^{35}$ But, if we watch these programmes now, it is clear that, whatever the journalistic independence of the producers, they continued to encode significant deference to doctors and to medical authority in their output, just as they did to scientists. And you might say that a range of prevailing doctors' attitudes to patients were carried over to audiences via the televisual technique and grammar of the time.

33 Singer 1966. See Boon 2015.

34 Boon 2008, 186; Jones 2013.

35 Loughlin 2000. 


\section{Conclusion}

This essay argues that television programmes advance propositions to laypeople about how to be a patient in relation to medical expertise; a 'patient position' is inscribed in these cultural products. It is striking to note that in all of our selected programmes covering three decades from 1958, patients are consistently presented as marginal to the medical stories being told. The 'inscribed' patient in every case is deferential to doctors or, worse, the anonymous object of medical practice, and so it follows that the role proposed to viewers must also have been to show deference and accept objecthood. This would not be what a reader of Alex Mold's argument would expect. It is difficult to tell whether this finding is an artefact of the programmes we have selected. There must in the archive be programmes that address, for example, Michael Balint's psychologised model of general practice, which recognised the psychodynamics of doctor-patient relations. ${ }^{36}$ After the publication of his 1955 book, The Doctor, His Patient, and the Illness, Balint's approach to the doctor-patient relationship, which explicitly made allowance for the effect of the doctor's behaviour on that of the patient, became influential throughout the sixties and beyond. Equally, it would be natural to expect the journalistically minded producers of Horizon to be drawn to the implications of Ivan Illich's critique of modern medicine, Medical Nemesis (1975). In either case, we might expect at least a richer rendering of the patient role and experience than in the programmes we have described here. As it is, a search of the BBC's online database of programmes yields no immediate candidates. ${ }^{37}$ But, to make such explorations is as much a matter of the historical sociology of medicine as it is a matter of the kind of close study of medical media that we have undertaken here. For the moment, we can only hope that we have succeeded in our aim of opening-up the question of patient roles in medical media for further study.

\section{Bibliography}

Akrich, Madeleine, "The De-Scription of Technical Objects", in Wiebe E. Bijker/ John Law (eds.), Geoffrey Bowker (translator) Shaping Technology/Building Society: Studies in Sociotechnical Change (Cambridge, Massachusetts 2003) 205-24

Anonymous, "Concern on experiments", The Guardian, 4 November 1971, 9

36 Shaul Bar-Haim 2018.

37 URL: https://genome.ch.bbc.co.uk/. Of television programmes, the only Illich programme antedates Medical Nemesis by three years. There are no television entries under Michael Balint. The Genome data derive from a scan of the Radio Times and therefore cannot be expected to record all coverage, as the listings are often quite parsimonious. 
Bar-Haim, Shaul, “The Drug Doctor”: Michael Balint and the Revival of General Practice in Postwar Britain", History Workshop Journal 86 (2018) 114-32

Boon, T., \& Gouyon, J. B., "The origins and practice of science on British television", in Martin Conboy/ John Steel (eds.), The Routledge Companion to British Media History (Routledge online 2014) 488-501

Boon, Timothy, “'The Televising of Science Is a Process of Television': Establishing Horizon, 1962-1967", The British Journal for the History of Science 48/1 (2015) $87-121$

Boon, Timothy, "On the Varieties of Medical Filmmaking: An Alternative Path to the Cultures of Bio-Medicine", in Mark Jackson (ed.), Oxford Handbook of the History of Medicine (Oxford 2011) 617-34

Boon, Timothy, "Programmes of Real Cultural Significance': BBC2, the Sciences and the Arts in the Mid-1960s", JBCTV 14/3 (2017) 324-43

Boon, Timothy, "Playing the Doctor, Playing the Patient: The Performance of Health Identities in Live Medical Television, 1958", in Christian Bonah/ Anja Laukötter (eds.), Body, Capital and Screens. Visual Media and the Healthy Self in the 20th Century (Amsterdam 2020)

Boon, Timothy, "Truffle-Hunters and Parachutists: In Search of the Audience for British Health Education Films, 1919-1945", in in Christian Bonah/ Anja Laukötter/ David Cantor (eds.), Health Education Films in the Twentieth Century (Rochester 2018) 327-50

Boon, Timothy, Films of Fact: A History of Science in Documentary Films and Television (London 2008)

Bruzzi, Stella, New Documentary (London 2006)

Butler, Judith, Bodies That Matter (New York 1993)

Callon, Michel, "Society in the making: the study of technology as a tool for sociological analysis", in Wiebe E. Bijker/ Thomas Parke Hughes/ Trevor J. Pinch, (eds). The social construction of technological systems: New directions in the sociology and history of technology (Cambridge, Massachusetts 1987) 83-103

Dopson, L, The Changing Scene in General Practice (London 1971)

Eco, Umberto, Travels in Hyperreality: Essays (London 1987)

Fisher, J.,"Foreword", in Sielmann, H., My Year with the Woodpeckers (London 1959) 9-11

Gill, Derek G., "The reorganisation of the National Health Service: some sociological aspects with special references to the role of the community physician", The Sociological Review 22/1, supplement (1974) 9-22

Goffman, Erving, The Presentation of Self in Everyday Life (London 1990)

Gouyon, Jean-Baptiste, BBC Wildlife Documentaries in the Age of Attenborough (Palgrave 2019)

Gouyon, Jean-Baptiste, "From engaged citizen to lone hero: Nobel Prize laureates on British television, 1962-2004", Public Understanding of Science 27/4 (2018) 446-57

Hermann, Edward, and Noam Chomsky, Manufacturing Consent: The Political Economy of the Mass Media (New York 1988)

Hornig, Susanna, "Television's NOVA and the construction of scientific truth", Critical Studies in Media Communication 7/1 (1990) 11-23

Illich, Ivan, Medical Nemesis: The Expropriation of Health (New York 1976) 
Johnstone, Keith, Impro: Improvisation and the Theatre (London 1981)

Jones, Allan, "Elite Science and the BBC: A 1950s Contest of Ownership", The British Journal for the History of Science 47/4 (2013) 1-23

Klein, Rudolf, "National health service: After reorganisation", The Political Quarterly 44/3 (1973) 316-28

Klein, Rudolf, "NHS Reorganisation: The Politics of the Second Best", The Lancet 300.7774 (1972) 418-20

Kohler G./ Milstein C., "Continuous cultures off used cells secreting antibody of predefined specificity", Nature 256.5517 (1975) 495-7

Leab, Daniel J., "Animators and Animals: John Halas, Joy Batchelor, and George Orwell's Animal Farm", Historical Journal of Film, Radio and Television 25/2 (2005) 231-49

Loughlin, Kelly, "'Your Life in Their Hands': The Context of a Medical-Media Controversy", Media History, 6/2 (2000) 177-88

Mold, Alex, Making the Patient-Consumer: Patient Organisations and Health Consumerism in Britain (Manchester 2016)

Nichols, Bill, "Documentary Theory and Practice”, Screen 17 (1976) 34-48

Singer, Aubrey, "Science Broadcasting", in BBC Lunch-Time Lectures, Series 4 (London 1966)

Small, Christopher, Musicking: The Meanings of Performing and Listening (Hanover 1998)

Stacey, Margaret, "The health service consumer: a sociological misconception", The Sociological Review 22/1 (1974) 194-200

\section{Episodes of television programmes}

'A Matter of Self Defence', BBC Horizon, produced by Michael Andrews, broadcast 7 January 1974, colour

'A Prize Discovery', BBC Horizon, produced by Chris La Fontaine, broadcast 29 April 1985, colour

'Are you Doing this for Me Doctor, or am I Doing it for You?', BBC Horizon, produced by Peter Jones, broadcast 14 February 1972, colour

'Forest Diaries', BBC (Natural History Unit) Look, 1963, B/W

'On Call to a Nation', BBC, written and produced by Richard Cawston, broadcast 22 October 1958, broadcast 22 October 1958, B/W (sound) 72 minutes. URL: https:// www.bbc.co.uk/iplayer/episode/p013ylyp/on-call-to-a-nation?suggid=p013ylyp [UK]

'The Unknown Forest', BBC (Natural History Unit), produced by Christopher Parsons, 1961, B/W (sound), 45 minutes

'Unarmed Hunters', BBC (Natural History Unit), produced by Christopher Parsons, 1963, B/W (sound), 30 minutes

'What Kind of Doctor', BBC Horizon, produced by Francis Gladstone and Brian Gibson, broadcast: 15 March 1971, colour 